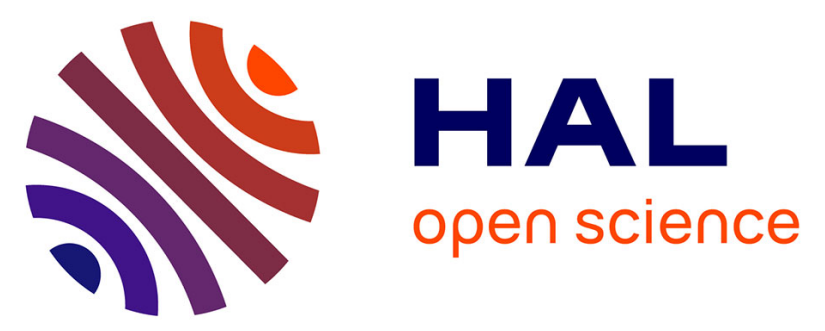

\title{
Population pharmacokinetics of single-dose amikacin in critically-ill patients with suspected ventilator-associated pneumonia
}

Charles Burdet, Olivier Pajot, Camille Couffignal, Laurence Armand-Lefèvre, Arnaud Foucrier, Cédric Laouénan, Michel Wolff, Laurent Massias, France Mentré

\section{To cite this version:}

Charles Burdet, Olivier Pajot, Camille Couffignal, Laurence Armand-Lefèvre, Arnaud Foucrier, et al.. Population pharmacokinetics of single-dose amikacin in critically-ill patients with suspected ventilatorassociated pneumonia. European Journal of Clinical Pharmacology, 2014, pp.doi:10.1007/s00228-0141766-y. 10.1007/s00228-014-1766-y . inserm-01079022

\section{HAL Id: inserm-01079022 https://www.hal.inserm.fr/inserm-01079022}

Submitted on 30 Oct 2014

HAL is a multi-disciplinary open access archive for the deposit and dissemination of scientific research documents, whether they are published or not. The documents may come from teaching and research institutions in France or abroad, or from public or private research centers.
L'archive ouverte pluridisciplinaire HAL, est destinée au dépôt et à la diffusion de documents scientifiques de niveau recherche, publiés ou non, émanant des établissements d'enseignement et de recherche français ou étrangers, des laboratoires publics ou privés. 


\section{Title}

Population pharmacokinetics of single-doseamikacin in critically-ill patients with suspected ventilator-associated pneumonia

\section{Authors}

C. Burdet ${ }^{1,2,3}$, O. Pajot ${ }^{4}$, C. Couffignal ${ }^{1,2,3}$, L. Armand-Lefèvre ${ }^{1,2,5}$, A. Foucrier ${ }^{6}$, C. Laouénan ${ }^{1,2,3}, M$. Wolff $^{1,2,6}$, L. Massias ${ }^{7}$ and F. Mentré ${ }^{1,2,3}$

\section{Authors affiliations}

${ }^{1}$ INSERM, IAME, UMR 1137, F-75018 Paris, France

${ }^{2}$ Univ Paris Diderot, IAME, UMR 1137, Sorbonne Paris Cité, F-75018 Paris, France

${ }^{3}$ AP-HP, Bichat Hospital, Biostatistics Department, F-75018 Paris, France

${ }^{3}$ V. DupouyHospital, Intensive Care Unit, F-95107Argenteuil, France

${ }^{4}$ AP-HP, Bichat Hospital, Bacteriology Department, F-75018 Paris, France

${ }^{5}$ AP-HP, Bichat Hospital, Intensive Care Unit, F-75018 Paris, France

${ }^{6}$ AP-HP, Bichat Hospital, Pharmacy Department, F-75018 Paris, France

\section{Corresponding author}

Charles Burdet

Postal address:

IAME, INSERM UMR 1137 - Université Paris Diderot

Service de Biostatistiques - HUPNVS - AP-HP

16 rue Henri Huchard

75018 Paris, France

Telephone number: 33 (0) 157277759

Fax number: 33 (0) 157277521

email : charles.burdet@inserm.fr

\section{Keywords}

Amikacin, Population pharmacokinetics, Intensive-care unit, Ventilator-associated pneumonia 


\section{Abstract}

$\underline{\text { Aims }}$

Modifications of antimicrobials'pharmacokinetic parameters have been reported in critically-ill patients, resulting in a risk of treatment failure. We characterizedamikacin pharmacokinetic variability in critically-ill patients with ventilator-associated pneumonia (VAP)and evaluated several dosing regimens.

\section{Methods}

We conducted a prospective multicenter study in critically-ill patients with presumptive diagnosis of Gram-negative bacilli (GNB) VAP. Patients empirically receivedimipenem and a single-dose ofamikacin, whichwas administered as a 30 -minuteinfusion $(20 \mathrm{mg} / \mathrm{kg})$. Concentrations were measured $0.5,1,8,16$ and 24 hours after beginning of infusion. Pharmacokinetic parameters were estimated using a population approach. Mainpharmacodynamic target was a ratio $\geq 10$ between the concentration achieved 1 hour after beginning of infusion $\left(C_{1 h}\right)$ and the minimal inhibitory concentration of the liable bacteria (MIC). We simulated individual $\mathrm{C}_{1 \mathrm{~h}}$ for severaldosing regimens by Monte Carlo method and computed $\mathrm{C}_{1 \mathrm{~h}} / \mathrm{MIC}$ ratios for MICs from 0.5 to $64 \mathrm{mg} / \mathrm{L}$.

\section{$\underline{\text { Results }}$}

Sixty patients (47 males), median (range) age and bodyweight: 61.5 years (28-84) and 78kg (45-126), respectively were included. Amikacin median $\mathrm{C}_{1 \mathrm{~h}}$ was $45 \mathrm{mg} / \mathrm{L}$ (22-87). Mean value (between-patients variability) for CL, V1, Q and V2 were 4.3L/h (31\%), 15.9L (22\%), 12.1L/h (27\%) and 21.4L (47\%), respectively. $\mathrm{CL}$ increased with $\mathrm{CrCL}(\mathrm{p}<0.001)$ and $\mathrm{V} 1$ with body weight $(\mathrm{p}<0.001)$ and $\mathrm{PaO}_{2} / \mathrm{FIO}_{2}$ ratio $(p<0.001)$. With a $25 \mathrm{mg} / \mathrm{kg}$ regimen, the pharmacodynamic targetwas achieved in $20 \%$ and $96 \%$ for aMICs of 8 and $4 \mathrm{mg} / \mathrm{L}$, respectively.

\section{Conclusion}


Amikacin clearance was decreased and its volume of distribution was increased as previously reported. A $\geq 25 \mathrm{mg} / \mathrm{kg}$ single-dose is needed for empirical treatment of GNB-VAP. 


\section{Introduction}

Ventilator-associated pneumonia (VAP), defined as pneumonia occurring more than $48 \mathrm{~h}$ after the initiation of mechanical ventilation, is the most common hospital-acquired infection in the intensive care unit (ICU) [1]. Many previously published studies have shown that early and appropriate antibiotic therapy is associated with better outcome in critically-ill patients with severe infections[2].The latest guidelines of the American Thoracic Society and Infectious Diseases Society of America recommend that the empirical antibiotic therapy for late-onset pneumonia or in patients with risk factors for infection by multidrug-resistant pathogens should include a combination of an anti-pseudomonal $\beta$-lactam and an anti-pseudomonalfluoroquinolone or an aminoglycoside such asamikacin[3].The superiority of once-daily dosing of aminoglycosides over multiple-daily dosing has been established[4]. However, no data supports a clinical benefit of a single-dose of aminoglycosides over multiple administrations. The rationale for an initial combination therapy is to broaden the antimicrobial spectrum of the empirical therapy; however some data suggest adverse effects linked to repeated administrations, such as adaptative resistance or nephrotoxicity.

Amikacin, like other aminoglycosides, exhibits a concentration-dependent killing and producesa prolonged post-antibiotic effect. Previousclinical studies have shown that aratioof 10 or more between the concentration achieved 1 hour after the beginning of a 30-minute infusion $\left(C_{1 h}\right)$ and the minimal inhibitory concentration (MIC) of the bacteria responsible of the infection was predictiveof therapeutic success $[5,6]$. Some authors recently suggested that a ratio between the area under the curve of concentration over time (AUC) and MIC (AUC/MIC) greater than 90 also has some predictive value for therapeutic success, with no difference in predictive capacities when compared to $\mathrm{C}_{1 \mathrm{~h}}$ / MIC ratio [7].Thosepharmacodynamic targets may be difficult to reach in criticallyill patients for several reasons. First, large interindividual variations of amikacin pharmacokinetic parameters have been reported [8-10], with variations of $C_{1 h}$ and $A U C$ as a consequence. This variability is partially explained by total body weight and creatinine clearance, which are the most 
frequently reported covariates of amikacin pharmacokinetic parameters[8-11]. Second, the current breakpoint of MICs defined by the European Committee on Antimicrobial Susceptibility Testing (EUCAST) for Enterobacteriaceaespecies and Pseudomonas aeruginosa is $8 \mathrm{mg} / \mathrm{L}$ [12].

Few authors investigated the amikacin dosage needed in a single infusion setting to achieve the defined pharmacodynamic target in a homogenous groupof patients hospitalised in ICU with suspected VAP.

Using data from a prospective clinical trial, we aimed (i) to characterize amikacin pharmacokinetic parameters and their variability in ICU patients with suspected VAP, (ii) to study covariates of amikacin pharmacokinetic parameters, and (iii) toevaluate several amikacin dosing regimens using Monte Carlo simulations.

\section{Material and methods}

\section{Patients and sampling}

This study is part of the IMPACTtrial, a prospective multicenterclinical trial conducted between 2009 and 2011 inthreelCUs, at Bichat university hospital, Paris, France, and Victor Dupouy hospital, Argenteuil, France (ClinicalTrials \#NCT00950222).

Patients were included in the trial if they presented the following criteria: mechanical ventilation for more than 48 hours, a clinical suspicion of Gram-negative bacilli VAP, risk factors for multidrug resistant bacteria, and if a microbiologic sample was obtained before initiation of antimicrobial therapy using blinded protected telescoping catheteror bronchoalveolar lavage. Clinical suspicion of VAP was defined by the onset of new lung infiltrates on chest radiography, fever greater than $38.3^{\circ} \mathrm{C}$, purulent tracheal aspirates or a leukocytosis $>10000 / \mathrm{mL}$. Risk factors for multidrug-resistant bacteria were antimicrobial therapy in the preceding 15 days or late-onset VAP ( $\geq 6$ days)[3]. Patients were not eligible if they were younger than 18-year-old, if they had renal failure requiring renal replacement therapy or received a treatment by imipenem or amikacin at the time of inclusion. 
Written consent was obtained from patients or their legal representative. The study was approved by the Ethics Committee of the Hôtel-Dieu university hospital (APHP, Paris).

All patients were treated with a combination of imipenem and amikacin.Imipenem was administered every 8 hours over a 30 -minute infusion and should not be changed for the first 48 hours. Doses ranged from $500 \mathrm{mg}$ to $1000 \mathrm{mg}$, according to creatinine clearance $(\mathrm{CrCL})$.Amikacintreatment consisted in onesingle 30-minute infusion of a suggested dose of $20 \mathrm{mg} / \mathrm{kg}$ administered the first day of antimicrobial therapy. This dose was recommended by guidelines at the time of this study was designed [3].

De-escalation therapy was encouraged after isolation of the Gram-negative pathogen and obtaining the results of susceptibility tests.

Usual clinical and demographic characteristics were recorded at ICU admission, as well as ventilator parameters, two scores for assessment of severity (SOFA [13]and SAPS-II [14])and routine biologic markers.

Blood samples were collected $0.5,1,8,16$ and 24 hours after the onsetof infusion. Exact times of beginning and end of infusion were recorded, as well as exact sampling times. Amikacin concentrations were determined by fluorescence polarization immunoassay using the amikacinInnofluor ${ }^{\circledast}$ kit[15]. The limit of quantification of the technique is $0.5 \mathrm{mg} / \mathrm{L}$, and coefficients of variation for intra- and inter-assay were $4.1 \%$ and $5.8 \%$, respectively.

\section{Population pharmacokinetic analysis}

\section{$\underline{\text { Basic model }}$}

Population pharmacokinetic analysis was performed using the Stochastic Approximation Expectation Minimization (SAEM) algorithm in Monolix v4.2 (Lixoft, Orsay, France, available at http://www.lixoft.com). This algorithm handles concentrations below the limit of quantification to 
improve parameters estimation [16]. We used the total dose administered to each patient for model building.

Both one- and two-compartment(s) models with first order elimination were tested[8, 10, 11, 17].

We used an exponential random effects model for each pharmacokinetic parameter. We assumed the random effects to have a normal distribution with a mean of 0 and a variance of $\omega^{2}$. Correlation ( $\rho$ ) between individual random effects was kept in the model if the estimated correlation coefficient was $\geq 0.2$. The residual error model was supposed to be additive, proportional or combined, with a being the standard deviation of the additive component and $\mathrm{b}$ the standard deviation of the proportional component.

The best model was chosen using the Bayesian information criteria (BIC), derived for each model from the computation of likelihood by importance sampling[18].

\section{Covariate model building}

The influence of the following covariates at initiation of treatment on amikacin pharmacokinetic parameters was tested: 3 demographic variables (age, gender and total body weight), 2 clinical variables (shock and edema score[19]), 2 severity scores (SOFA[13] andSAPS-II[14]), 2 ventilatorrelated parameters (PEEP and $\mathrm{PaO}_{2} / \mathrm{FIO}_{2}$ ratio) and 3 biochemical markers (serum albumin, total bilirubin and 4-hour creatinine clearance). Four-hour creatinine clearance was calculated using serum creatinine level and a 4-hour urine collection at the day of inclusion. This approach has been validated for monitoring renal function in critically-ill patients[20]. Missing values for tested covariates were imputedto the median value observed in the analysis population.Steps for selection of covariate model are described in Online Resource 1.

\section{Final model determination}


We graphically studied the influence of covariates on their related pharmacokinetic parameters.

Outliers were studied and excluded from analysis when there was a suspicion of incomplete data collection, in particular for creatinine clearance which was estimated using a 4-hour urine collection. Patients for whom covariates had been imputed were also excluded. The covariate model was adjusted to the reduced population obtained after exclusion of these patients, and a backward selection method was used in order to obtain a final model in which all covariates had a $p$-value < 0.05 using the likelihood-ratio test.

The coefficient estimated for creatinine clearance was compared to 1 using the likelihood ratio test.

\section{Model evaluation}

Evaluation of the final model was conducted using graphical methods. Basic goodness-of-fit plots were used, as well as the individual weighted residuals (IWRES) and the normalized prediction distribution errors (NPDE) over time and the visual predictive check (VPC).NPDE and VPC were generated using 500 Monte Carlo simulations.

\section{Evaluation of doses by simulation}

Using the estimated distribution of amikacin pharmacokinetic parameters in the final model with covariates, we simulated amikacin concentration obtained 1 hour after the start of a 30-minute infusion and AUC for 1000 patients by Monte Carlo simulation for several dosing regimen. This timing for amikacin sampling is commonly used for studying amikacin efficacy[17].For pharmacokinetic simulations, we randomly re-sampled 1000 vectors of covariatesamong those observed in the patients included in the analysis and simulated individual pharmacokinetic parameters from their estimated distribution in the final model with covariates. Simulated doseregimens were the following: $20,25,30,35$ and $40 \mathrm{mg} / \mathrm{kg}$. We computed the probability to achieve a $\mathrm{C}_{1 \mathrm{~h}} / \mathrm{MIC}$ ratio $\geq 10$ and an AUC/MIC ratio $\geq 90$ for MICs ranging from $0.25 \mathrm{mg} / \mathrm{L}$ to $64 \mathrm{mg} / \mathrm{L}$ for each or these dosing regimens. These values are usually observed in clinical practice 
(http://www.eucast.org/mic_distributions/), with an $8 \mathrm{mg} / \mathrm{l}$ susceptibility breakpoint for Enterobacteriaceaespecies and Pseudomonas aeruginosa.

\section{Results}

\section{Patients' characteristics}

Of the 61 patients included in the IMPACTtrial, one had a kinetic profile which was not compatible with a unique injection and was withdrawn from analysis. Thus, data from 60 patients were available for modelling. Patients' characteristics are presented in Table 1. Median ( $\min -\max )$ age and total body weight were respectively 61.5 years $(28-84)$ and $78 \mathrm{~kg}(45-126)$, andmost patients were males ( $n=47,78 \%)$. At inclusion, 26 patients hadseptic shock (43\%). Median SAPS-II and SOFA scores were $42(19-90)$ and $7(2-17)$, respectively, andmedian 4-hour creatinine clearance was $82 \mathrm{~mL} / \mathrm{min}$ $(4-412)$.

\section{Pharmacokinetic data and modelling}

A total of 291 values of amikacin concentrations were available, with a median of 5 per patient ( $3-$ 5). Median amikacin dose administered was $20 \mathrm{mg} / \mathrm{kg}(11-28)$. Median serum concentration observed 1 hour after the beginning of infusion was $45 \mathrm{mg} / \mathrm{L}(22-87)$. Individual observed concentrations are presented in Figure 1. Fourteen values (4.8\%) of amikacin concentration were below the limit of quantification.

Serum concentrations were best described by a 2-compartment model with a combined residual error model (Online Resource 2). Correlations between estimates in the basic model were $\geq 0.2$ between all individual random effects, and thus kept in the analysis. In this model, amikacin clearance (CL) was estimated to $4.0 \mathrm{~L} / \mathrm{h}$, central volume of distribution (V1) to $15.3 \mathrm{~L}$, peripheral volume of distribution (V2) to $22.1 \mathrm{~L}$ and inter-compartmental clearance (Q) to $12.2 \mathrm{~L} / \mathrm{h}$ (Table 2). Their relative standard errors were satisfactory, all being $<10 \%$. The inter-individual variability of pharmacokinetic parameters ranged from $30 \%$ for Q, to $60 \%$ for $\mathrm{CL}$. Estimates of inter-individual 
variability of pharmacokinetic parameters were also satisfactory (Table 2). The goodness of fit plots of this model without covariate did not show any model deficiency (data not shown).

Among the 12studiedcovariates, 8 were significantly associated with the individual Bayes estimates of pharmacokinetic parameters (Online Resource 1).The best model included 4 covariates (Online resource 1): creatinine clearance for $\mathrm{CL}$, total body weight and $\mathrm{PaO}_{2} / \mathrm{FIO}_{2}$ ratio for $\mathrm{V} 1$, and creatinine clearance for V2. Two patients presented a low creatinine clearance but a high amikacin clearance. Their individual fits were satisfactory, and we hypothesised that their urine collection was incomplete. They were excluded from the analysis. In another patient, amikacin clearance was estimated to $11 \mathrm{~mL} / \mathrm{min}$, but creatinine clearance was missing and had been imputed to the median value. The 5 patients in whom creatinine clearance was not available were excluded. The 4-covariate model was adjusted to the 53 remaining patients.

Creatinine clearance was no longer a significant covariate for V2 $(p=0.4)$, and the final model included 3 covariates: creatinine clearance $(p<0.001)$ for $C L$, total body weight $(p<0.001)$ and $\mathrm{PaO}_{2} / \mathrm{FIO}_{2}$ ratio $(\mathrm{p}<0.001)$ for $\mathrm{V} 1$ (Table 2$)$. The coefficient for creatinine clearance on $\mathrm{CL}$ was significantly different from $1(p<0.001)$. The variations of pharmacokinetic parameters according to covariates are presented in Figure 2 . All three of them were positively correlated with the pharmacokinetic parameters. Amikacin clearance was estimated in the final model at $4.3 \mathrm{~L} / \mathrm{h}$ (72 $\mathrm{mL} / \mathrm{min}$ ), $\mathrm{V} 1$ at $15.9 \mathrm{~L}$ and $\mathrm{V} 2$ at $21.4 \mathrm{~L}$ (Table 2).Variance - covariance matrix between the individual random effects is presented in Online Resource 3.

Goodness-of-fit plots did not show any model misspecification. The IWRES and NPDE were centered to zero and did not show any trend over time (Online Resource 4). The VPC did not show any model deficiency (Figure 3).

\section{Pharmacokinetic simulations}


Probabilities to achieve a $\mathrm{C}_{1 \mathrm{~h}} / \mathrm{MIC}$ ratio $\geq 10$ according to the single-dose of amikacinsimulated and MICs are presented in Figure 4. A20 mg/kg dosewas sufficient to achieve the pharmacokinetic target in $100 \%$ of patients for a MIC of $2 \mathrm{mg} / \mathrm{L}$ or less. With this dose only $80 \%$ and $4 \%$ of patients achieved the target for a MIC of 4 and $8 \mathrm{mg} / \mathrm{L}$, respectively. With a $25 \mathrm{mg} / \mathrm{kg}$ simulated infusion, the probability to reach the target was $96 \%$ for a MIC of $4 \mathrm{mg} / \mathrm{L}$ and $20 \%$ for a MIC of $8 \mathrm{mg} / \mathrm{L}$. With the $40 \mathrm{mg} / \mathrm{kg}$ regimen, the probability to achieve a $\mathrm{C}_{1 \mathrm{~h}} / \mathrm{MIC}$ ratio $\geq 10$ was $80 \%$ for a MIC of $8 \mathrm{mg} / \mathrm{L}$ (Figure 5).Online Resource 5 presents the boxplots of the 1000 simulated $\mathrm{C}_{1 \mathrm{~h}} / \mathrm{MIC}$ ratio for a $\mathrm{MIC}$ of $8 \mathrm{mg} / \mathrm{L}$, for doses from 20 to $40 \mathrm{mg} / \mathrm{kg}$.

Results were similar when considering the target of AUC/MIC $\geq 90$ (Online Resource 6). With a dose of $20 \mathrm{mg} / \mathrm{kg}$, 90\% of patients achieved the target for a MIC of $2 \mathrm{mg} / \mathrm{L}$ or less, but this proportion was below $20 \%$ for a MIC value of $8 \mathrm{mg} / \mathrm{L}$. Simulations for a dose of $25 \mathrm{mg} / \mathrm{kg}$ showed that $69 \%$ of patients achieved the pharmacodynamic target for a MIC of $4 \mathrm{mg} / \mathrm{L}$, but only $22 \%$ did for a MIC of $8 \mathrm{mg} / \mathrm{L}$. An increase to $40 \mathrm{mg} / \mathrm{kg}$ led to an increase of the probability to reach the pharmacodynamic target to $90 \%$ and $52 \%$ for a MIC of $4 \mathrm{mg} / \mathrm{L}$ or $8 \mathrm{mg} / \mathrm{L}$, respectively.

\section{Discussion}

The present study confirms that the $20 \mathrm{mg} / \mathrm{kg}$ single-dose regimen traditionally used is not adequatebased on the analysed pharmacokinetic and pharmacodynamic indices and thatamikacin dosing regimen should be increased to at least $25 \mathrm{mg} / \mathrm{kg}$ for critically-ill patients when initiating empirical amikacin therapy for VAP caused by a Gram-negative rod. This increase has been recently suggested by Taccone et al [17]. To our knowledge, few data supported this recommendation[21, 22]. Those studies did not use a population approach and were performed in patients with severe sepsis or septic shock, thereby gathering patients with different varieties of infection. Although the influence of the nature of infection has not been thoroughly examined, some authors suggested that the clinical diagnosis might influence the pharmacokinetic parameters of aminoglycosides [10]. We focused our analysis on an homogenous group of patients. Our simulation-based analysis, using data 
from a prospective multicenter trial and a solid methodology, confirms theresults of Tacconeet al [17], and suggest that a higher initial dose is necessary, at least in patients requiring mechanical ventilation.

A comparative study of different initial amikacin dosing regimen would confirm our conclusions. It would also allow to study the impact of higher doses on renal function. Nephrotoxicity is a wellknown adverse effect of aminoglycoside therapy. However, this effect has beenassociated with duration of therapy[23].Available studies suggest that short-course treatments would allow to minimize toxicity while keeping maximal efficacy [24]. In the majority of severe infections, aminoglycosides are administered as a single infusion in combined antimicrobial therapy. Higher single doses would therefore have potentially limited or no effect on renal function, as suggested by recent studies [21, 22]. It should also be noticed that neuromuscular blockade might have an increased frequency when using higher doses of aminoglycosides [25]. Its main manifestation is respiratory weakness, and this side effect is reversible. It would have a limited impact on patients with mechanical ventilation.

Another result is thatamikacin clearance and volume of distribution were estimated to approximately $70 \mathrm{~mL} / \mathrm{min}$ and $37 \mathrm{~L}$, respectively. These values were in accordance with published data on ICU patients. This confirms the issues observed in antimicrobial pharmacokinetic parameters in critically-ill patients $[26,27]$, i.e.adecreaseof drug clearance and an increaseof volume of distribution [28-32]. Significant covariates were 4-hour creatinine clearance for amikacin clearance, and total body weight and $\mathrm{PaO}_{2} / \mathrm{FlO}_{2}$ ratio for central volume.

The association between total body weight and volume of distribution has already been reported [9, $10,33]$, and administered amikacin doses are commonly adjusted to total body weight. It is still not clear which measure of body size best describes pharmacokinetic parameters.A recent meta-analysis explored the relationship between drug clearance and body size metrics [34]. The authors found that lean body weight to the exponent $2 / 3$ was more suitable for describing the relationship between 
drug clearance and body size. However, they did not question the link between the volume of distribution and body size, and this conclusion may not apply for all pharmacokinetic parameters. As body size was not collected in the IMPACT trial, we could not investigate the effect of this weight metrics or of body mass index on amikacin pharmacokinetic parameters. For hydrophilic drugs such as aminoglycosides, data on the influence of lean body weight and drugs volume of distribution are lacking and would be of interest.

The BIC was not improved by adding total body weight as a covariate for V2. This is quite unexpected, and V2 might represent a weight-independent compartment in which amikacin accumulates. It has previously been shown that total urine recovery of amikacin isnot complete 24 hours after its administration, and that aminoglycosides including amikacin accumulates in the kidney[35, 36].

We found a high interindividual variability in amikacin pharmacokinetic parameters as previously reported in studies performed among critically-ill patients [8, 37]. Significant covariates reducedthis variability, with a 50\% maximal decrease for amikacinCL in our study. To our knowledge, no published covariate model could fully explain the observed interindividual variability. It is therefore highly probable that inside diagnosis-homogenous groups of patients, subpopulations exist that are not individualized by usual covariates. Such variability makes the choice of the optimal dosing strategy extremely challenging from an individual perspective. Considering the absence of severe adverse effect expected in a single-dose setting,mechanically-ventilated patients in intensive care units should receive a high amikacine dose in order to maximize the probability of pharmacodynamic target attainment. Further studies should furthermore focus on identification of covariates allowing for reducing the high unexplained interindividual variability.

The main limitation of this study is that it was restricted to a limited number of patientswho had a suspicion on VAP. Therefore the results may not apply to patients who do not require mechanical ventilation. Nevertheless, the French surveillance network of nosocomial infections 
recently reported that about $60 \%$ of patients hospitalized in ICU would require mechanical ventilation during their stay[38]. Another limitation is the use of the MIC breakpoint for Monte Carlo simulations. To our knowledge, no published data report the distribution of MICs for Gram-negative bacilli responsible for infection in intensive care units. As bacteria involved in infection of critically-ill patients frequently have higher MICs than those isolated from patients hospitalised in other wards, we did not use published MICs distributions that gather strains obtained from all wards. A recent study of MIC breakpoints based on simulations suggested that pharmacokinetic - pharmacodynamic breakpoints are similar to those defined by the EUCAST or the CLSI [39]. In the empirical setting, the worst-case assumption should be preferred when initiating an antimicrobial therapy.This approach is currently used for pharmacokinetic-pharmacodynamic simulations $[17,40,41]$. However, it is likely that the majority of Gram-negative rods involved in critical infections have a MIC below $8 \mathrm{mg} / \mathrm{L}$. For a MIC of $4 \mathrm{mg} / \mathrm{L}, 96 \%$ of patients achieved a $\mathrm{C}_{1 \mathrm{~h}} / \mathrm{MIC}$ ratio $\geq 10$ after a dose of $25 \mathrm{mg} / \mathrm{kg}$ in our simulations.

In conclusion, amikacin pharmacokinetic parameters values were similar to those previously reported. This study confirms recent results for the determination of the initial amikacin dose required in critically-ill patients. An empirical dose of $25 \mathrm{mg} / \mathrm{kg}$ or more is needed to achieve the amikacinpharmacodynamic predictors of clinical efficacyin Gram-negative bacilli infections. Other studies are needed to prospectively evaluate these conclusions in order to improve the management of patients with severe infections.

\section{Authors' contributions}

FM, LAL, MW and OP conceived the study

AF, MW and OP provided medical care to trial participants

LM performed the pharmacological assays

$\mathrm{CB}, \mathrm{CC}, \mathrm{CL}$ and $\mathrm{FM}$ performed the statistical analysis

$\mathrm{CB}, \mathrm{FM}, \mathrm{MW}$ and $\mathrm{OP}$ wrote the first draft of the manuscript. All authors read and agreed with the manuscript in its published version. 


\section{Competing interests}

All authors have completed the Unified Competing Interest form (available on request from the corresponding author) and declare no support from any organization for the submitted work; no financial relationship with any organisation that might have an interest in the submitted work in the previous 3 years; no other relationships or activity that could appear to have influenced the submitted work.

This studywasfunded by the Contrat d'Initiation à la Recherche Clinique 2006 (Assistance PubliqueHôpitaux de Paris, Département de la Recherche Clinique et du Développement, CRC 06049) 


\section{References}

1 Bouadma L, Wolff M, Lucet JC (2012) Ventilator-associated pneumonia and its prevention. Curr Opin Infect Dis 25 (4): 395-404

2 Zahar JR, Timsit JF, Garrouste-Orgeas M, Francais A, Vesin A, Descorps-Declere A, Dubois Y, Souweine B, Haouache H, Goldgran-Toledano D, Allaouchiche B, Azoulay E, Adrie C (2011) Outcomes in severe sepsis and patients with septic shock: pathogen species and infection sites are not associated with mortality. Crit Care Med 39 (8): 1886-1895

3 (2005) Guidelines for the management of adults with hospital-acquired, ventilatorassociated, and healthcare-associated pneumonia. Am J Respir Crit Care Med 171 (4): 388416

4 Barza M, loannidis JP, Cappelleri JC, Lau J (1996) Single or multiple daily doses of aminoglycosides: a meta-analysis. BMJ 312 (7027): 338-345

5 Moore RD, Lietman PS, Smith CR (1987) Clinical response to aminoglycoside therapy: importance of the ratio of peak concentration to minimal inhibitory concentration. J Infect Dis 155 (1): 93-99

6 Kashuba AD, Nafziger AN, Drusano GL, Bertino JS, Jr. (1999) Optimizing aminoglycoside therapy for nosocomial pneumonia caused by gram-negative bacteria. Antimicrob Agents Chemother 43 (3): 623-629

7 Zelenitsky SA, Harding GK, Sun S, Ubhi K, Ariano RE (2003) Treatment and outcome of Pseudomonas aeruginosa bacteraemia: an antibiotic pharmacodynamic analysis. J Antimicrob Chemother 52 (4): 668-674

8 Delattre IK, Musuamba FT, Nyberg J, Taccone FS, Laterre PF, Verbeeck RK, Jacobs F, Wallemacq PE (2010) Population pharmacokinetic modeling and optimal sampling strategy for Bayesian estimation of amikacin exposure in critically ill septic patients. Ther Drug Monit 32 (6): 749-756

9 Bacopoulou F, Markantonis SL, Pavlou E, Adamidou M (2003) A study of once-daily amikacin with low peak target concentrations in intensive care unit patients: pharmacokinetics and associated outcomes. J Crit Care 18 (2): 107-113

10 Romano S, Del Mar Fdez de Gatta M, Calvo V, Mendez E, Dominguez-Gil A, Lanao JM (1998) Influence of clinical diagnosis in the population pharmacokinetics of amikacin in intensive care unit patients. Clin Drug Investig 15 (5): 435-444

11 Lugo G, Castaneda-Hernandez G (1997) Relationship between hemodynamic and vital support measures and pharmacokinetic variability of amikacin in critically ill patients with sepsis. Crit Care Med 25 (5): 806-811

12 EUCAST Breakpoint tables for interpretation of MICs and zone diameters. Consulted on 03/02/2013, available at :

http://www.eucast.org/fileadmin/src/media/PDFs/EUCAST files/Breakpoint tables/Breakpo int table $\vee$ 3.1.pdf.

13 Vincent JL, Moreno R, Takala J, Willatts S, De Mendonca A, Bruining H, Reinhart CK, Suter PM, Thijs LG (1996) The SOFA (Sepsis-related Organ Failure Assessment) score to describe organ dysfunction/failure. On behalf of the Working Group on Sepsis-Related Problems of the European Society of Intensive Care Medicine. Intensive Care Med 22 (7): 707-710

14 Le Gall JR, Lemeshow S, Saulnier F (1993) A new Simplified Acute Physiology Score (SAPS II) based on a European/North American multicenter study. JAMA 270 (24): 2957-2963

15 White LO, Holt HA, Reeves DS, MacGowan AP (1997) Evaluation of Innofluor fluorescence polarization immunoassay kits for the determination of serum concentrations of gentamicin, tobramycin, amikacin and vancomycin. J Antimicrob Chemother 39 (3): 355-361 
Samson A, Lavielle M, Mentré $F$ (2006) Extension of the SAEM algorithm to left-censored data in non-linear mixed-effects model: application to HIV dynamics model. Comput Stat Data Anal 51 (3): 1562-1574

17 Taccone FS, Laterre PF, Spapen H, Dugernier T, Delattre I, Layeux B, De Backer D, Wittebole $X$, Wallemacq P, Vincent JL, Jacobs F (2010) Revisiting the loading dose of amikacin for patients with severe sepsis and septic shock. Crit Care 14 (2): R53 Lavielle M, Mentré $F$ (2007) Estimation of population pharmacokinetic parameters of saquinavir in HIV patients with the MONOLIX software. J Pharmacokinet Pharmacodyn 34 (2): 229-249

19 Gomez CM, Cordingly JJ, Palazzo MG (1999) Altered pharmacokinetics of ceftazidime in critically ill patients. Antimicrob Agents Chemother 43 (7): 1798-1802

20 Pickering JW, Frampton CM, Walker RJ, Shaw GM, Endre ZH (2012) Four hour creatinine clearance is better than plasma creatinine for monitoring renal function in critically ill patients. Crit Care 16 (3): R107

21 Galvez R, Luengo C, Cornejo R, Kosche J, Romero C, Tobar E, Illanes V, Llanos O, Castro J (2011) Higher than recommended amikacin loading doses achieve pharmacokinetic targets without associated toxicity. Int J Antimicrob Agents 38 (2): 146-151

22 Mahmoudi L, Mohammadpour AH, Ahmadi A, Niknam R, Mojtahedzadeh M (2013) Influence of sepsis on higher daily dose of amikacin pharmacokinetics in critically ill patients. Eur Rev Med Pharmacol Sci 17 (3): 285-291

23 Bertino JS, Jr., Booker LA, Franck PA, Jenkins PL, Franck KR, Nafziger AN (1993) Incidence of and significant risk factors for aminoglycoside-associated nephrotoxicity in patients dosed by using individualized pharmacokinetic monitoring. J Infect Dis 167 (1): 173-179

24 Drusano GL, Ambrose PG, Bhavnani SM, Bertino JS, Nafziger AN, Louie A (2007) Back to the future: using aminoglycosides again and how to dose them optimally. Clin Infect Dis 45 (6): 753-760

25 Snavely S, Hodges G (1984) The neurotoxicity of antibacterial agents. Ann Intern Med 101 (1): 92-104

26 Roberts JA, Lipman J (2009) Pharmacokinetic issues for antibiotics in the critically ill patient. Crit Care Med 37 (3): 840-851; quiz 859

27 Pea F, Viale P, Furlanut M (2005) Antimicrobial therapy in critically ill patients: a review of pathophysiological conditions responsible for altered disposition and pharmacokinetic variability. Clin Pharmacokinet 44 (10): 1009-1034 Lode H, Grunert K, Koeppe P, Langmaack H (1976) Pharmacokinetic and clinical studies with amikacin, a new aminoglycoside antibiotic. J Infect Dis 134 SUPPL: S316-322

29 Tormo C, Abad FJ, Ronchera-Oms CL, Parra V, Jimenez NV (1995) Critically-ill patients receiving total parenteral nutrition show altered amikacin pharmacokinetics. Clin Nutr 14 (4): 254-259

30 Marik PE (1993) Aminoglycoside volume of distribution and illness severity in critically ill septic patients. Anaesth Intensive Care 21 (2): 172-173

31 Bressolle F, Gouby A, Martinez JM, Joubert P, Saissi G, Guillaud R, Gomeni R (1996) Population pharmacokinetics of amikacin in critically ill patients. Antimicrob Agents Chemother 40 (7): 1682-1689

32 Marik PE, Havlik I, Monteagudo FS, Lipman J (1991) The pharmacokinetic of amikacin in critically ill adult and paediatric patients: comparison of once- versus twice-daily dosing regimens. J Antimicrob Chemother 27 Suppl C: 81-89

33 Mar Fernandez de Gatta MD, Victoria Calvo M, Ardanuy R, Dominguez-Gil A, Lanao JM, Moreno SR (2009) Evaluation of population pharmacokinetic models for amikacin dosage individualization in critically ill patients. J Pharm Pharmacol 61 (6): 759-766

34 McLeay SC, Morrish GA, Kirkpatrick CM, Green B (2012) The relationship between drug clearance and body size: systematic review and meta-analysis of the literature published from 2000 to 2007. Clin Pharmacokinet 51 (5): 319-330 
35 Edwards CQ, Smith CR, Baughman KL, Rogers JF, Lietman PS (1976) Concentrations of gentamicin and amikacin in human kidneys. Antimicrob Agents Chemother 9 (6): 925-927 French MA, Cerra FB, Plaut ME, Schentag JJ (1981) Amikacin and gentamicin accumulation pharmacokinetics and nephrotoxicity in critically ill patients. Antimicrob Agents Chemother 19 (1): 147-152

37 Joubert P, Bressolle F, Gouby A, Doucot PY, Saissi G, Gomeni R (1999) A population approach to the forecasting of amikacin plasma and urinary levels using a prescribed dosage regimen. Eur J Drug Metab Pharmacokinet 24 (1): 39-46

38 Savey A, Machut A (2012) Surveillance des infections nosocomiales en réanimation adulte. Réseau REA-Raisin, France, Résultats 2011. Available at http://www.invs.sante.fr/\%20fr/Publications-et-outils/Rapports-et-syntheses/Maladiesinfectieuses/2013/Surveillance-des-infections-nosocomiales-en-reanimation-adulte. In: ed. Frei CR, Wiederhold NP, Burgess DS (2008) Antimicrobial breakpoints for gram-negative aerobic bacteria based on pharmacokinetic-pharmacodynamic models with Monte Carlo simulation. J Antimicrob Chemother 61 (3): 621-628

40 Carlier M, Noe M, De Waele JJ, Stove V, Verstraete AG, Lipman J, Roberts JA (2013) Population pharmacokinetics and dosing simulations of amoxicillin/clavulanic acid in critically ill patients. J Antimicrob Chemother 68 (11): 2600-2608

41 de Montmollin E, Bouadma L, Gault N, Mourvillier B, Mariotte E, Chemam S, Massias L, Papy E, Tubach F, Wolff M, Sonneville R (2014) Predictors of insufficient amikacin peak concentration in critically ill patients receiving a $25 \mathrm{mg} / \mathrm{kg}$ total body weight regimen. Intensive Care Med 